Research Journal of Applied Sciences, Engineering and Technology 6(12): 2141-2152, 2013

DOI:10.19026/rjaset.6.3838

ISSN: 2040-7459; e-ISSN: 2040-7467

(C) 2013 Maxwell Scientific Publication Corp.

\begin{tabular}{lll}
\hline Submitted: December 07, 2012 & Accepted: January 17, 2013 & Published: July 30, 2013
\end{tabular}

\title{
Research Article \\ An Order Allocation Model based on the Competitive and Rational Pre-Estimate Behavior in Logistics Service Supply Chain
}

\author{
Weihua Liu, Meiying Ge and Chunling Liu \\ School of Management, Tianjin University, 92, Weijin Road, Nankai District, Tianjin, China
}

\begin{abstract}
In the actual order allocation process of Logistics Service Supply Chain (LSSC), Functional Logistics Service Providers (FLSPs) are strategic: they will pre-estimate the order allocation results to decide whether or not to participate in order allocation. Considering a two-echelon Logistics Service Supply Chain (LSSC) consisting of one Logistics Service Integrator (LSI) and several competitive FLSPs, we establish an order allocation optimization model of LSSC based on the pre-estimate and competitive behavior of FLSPs. The model considers three objectives: to minimize the cost of LSI, to maximize the order satisfaction of FLSPs and to match the different logistics capacities of FLSPs as much as possible. Numerical analysis is performed to discuss the effects of the competition among FLSPs on the order allocation results. The results show that with the rational expectations equilibrium, competitions among FLSPs help improve the comprehensive performance of LSSC.
\end{abstract}

Keywords: Competition, logistics service supply chain, order allocation, rational expectations equilibrium

\section{INTRODUCTION}

In a Logistics Service Supply Chain (LSSC), the logistics service integrator (LSI) generally has many functional logistics service providers (FLSPs) (Choy et al., 2007; Liu et al., 2011). Upon receiving the demand order of customers, LSI allocates it to FLSPs, who provide the corresponding logistics service capacity to fulfill the logistics service order. We call this process "demand order allocation", and the model established according to this process is known as the "order allocation model".

Actual individual behavior has a significant impact on operational decisions in the operation management system. Thus, innovative research on behavior theory is necessitated to conduct operation management (Bendoly et al., 2006). In previous studies on order distribution in the supply chain, enterprises involved in order allocation always accepted orders passively; however, in the actual order allocation process, the strategic behaviors of FLSPs, especially pre-estimate behaviors, have an important influence on the order allocation results. Applying pre-estimate behavior to order allocation, FLSPs will not accept orders passively; nevertheless, they will consider the profit and the possibility of getting the order before participating in order allocation. In this study, we intend to introduce the pre-estimate behavior of FLSPs to order allocation modeling, taking into account the competition among FLSPs and to explore the effects of competitive factors on the order allocation results. This study aims to answer the following important questions:

- In order allocation, FLSPs not only have preestimate behavior, but also have competition behavior, therefore, how can we get Rational Expectations Equilibrium (REE) of FLSPs and use it as a constraint condition of participating in order allocation?

- Competition is useful in order allocation which has been proved by many researches (Forker and Stannack, 2000; Babich et al., 2007; Jin and Ryan, 2012). However, what are the effects of competition intensity on order allocation? How can LSI choose a moderate degree of competition for order allocation?

- In order allocation, what are the effects when LSI adds different types of FLSPs? Is it right that the more the best type FLSPs added, the better performance of order allocation is?

\section{LITERATURE REVIEW}

The topic of this study mainly involves two research fields: Order allocation in the supply chain and the rational expectations equilibrium. The literature review will focus on relevant studies to expound research progress and deficiencies in these two fields.

Supply chain order allocation and supplier competition: Previous studies on the order allocation

Corresponding Author: Weihua Liu, School of Management, Tianjin University, 92, Weijin Road, Nankai District, Tianjin, China

This work is licensed under a Creative Commons Attribution 4.0 International License (URL: http://creativecommons.org/licenses/by/4.0/). 
of the supply chain (Chan et al., 2001; Menon and Schrage, 2002; Kawtummachai and Hop, 2005) have considered the maximal order service level and the minimum procurement cost and the perspective mainly focuses on the manufacturing industry. A number of studies (Kawtummachai and Hop, 2005; Demirtas and Üstün, 2008; Liu et al., 2011) have solved this problem using a multi-objective programming method, such as multi-objective integer programming (Ji, 2005; Demirtas and Üstün, 2008), 0-1 planning (Xiang et al., 2006) and multi-agent approach (Ta et al., 2005). When the models are complicated, a combination of genetic algorithms and heuristic rules (Ji, 2005) or Particle swarm optimization (PrasannaVenkatesan and Kumanan, 2012) is commonly used. In addition, many scholars use numerical experiments to reveal many interesting findings (Chaharsooghi et al., 2011).

Competition among suppliers has a significant influence on supply chain performance. In recent years, competition among suppliers has been considered in several studies on order allocation. For instance, in the order allocation of manufacturers, for the difference in order completion time, supplies complete based on price; thus, manufacturers will allocate orders according to the two objectives of price and order completion time of suppliers (Babich, 2006; Xia et al., 2012; Jin and Ryan, 2012). Competition also exists for the quantity of supplies (Forker and Stannack, 2000; Yue et al., 2009). Several scholars discuss the effects of supplier competition on order allocation based on supply chain risk, whose investigation has been a research hot spot in recent years (Babich et al., 2007; Liu et al., 2011; Yang et al., 2012).

Rational expectations hypothesis and rational expectations equilibrium: Initially proposed by Muth (1961), the rational expectations hypothesis has been widely applied in economics. The rational expectations hypothesis suggests that no systematic bias should emerge between economic operation results and people's expectations (Qi et al., 2010). Recently, the rational expectations hypothesis has been applied to supply chain management, especially in contact coordination, in which the rational expectations of both cooperation partners are consistent with the actual operation results (i.e., Rational Expectations Equilibrium (REE) exists). Several scholars have introduced the REE to supply chain management, such as the REE between the upstream and downstream supply chain (Su and Zhang, 2008), REE analysis of the newsvendor model (Du, 2009) and supply chain pricing (Qi et al., 2010; Wang et al., 2011; Yang et al., 2011). However, the REE is still not applied to the order allocation of supply chains, especially the order allocation of the LSSC and existing studies on order allocation have ignored the impact of the pre-estimate behavior of FLSPs on supply chain decision making.
Nevertheless, the behavior of participants in the supply chain, especially rational pre-estimate behavior, plays a significant role in operation management (Bendoly et al., 2006). Therefore, in the current study, the REE is applied to the order allocation problem to explore the effects of the pre-estimate behavior of FLSPs on LSSC order allocation, which provides a reference for LSI to scientifically manage the supply chain.

Existing studies on supply chain order allocation ignore the rational expectations behavior of supply chain members and the influence of competition among FLSPs on supply chain decisions, but these two factors exist in actual LSSC operations. Therefore, introducing these two factors to order allocation in LSSC has a more practical value. For this reason, this study establishes an order allocation model in competitive environment with three objectives: the total cost of LSI, satisfaction of FLSPs and logistics capacity matching degree, considering pre-estimate behavior and the REE theory. Based on the order allocation model, we explore the effects of pre-estimate behavior and competitive factors on order allocation and analyze the impact of different competition intensities on supply chain performance.

\section{MODEL FORMULATION AND SOLUTION}

In this section, the order allocation optimization model of the LSSC is established. Two constraints are defined in this model. One constraint is the equivalence between the capacities of FLSPs and the order demands of customers, which will be discussed in section (Problem description and assumptions). The other is the rational expectations conditions of the participation of each FLSP in order allocation, which will be discussed in Section (Rational expectation constraint of FLSP considering REE and competition behavior) by considering the pre-estimate behavior and competition of FLSPs. The model has three objective functions, namely, to maximize the capacity matching degree of FLSPs (section the formulation of capacity matching degree); to maximize the satisfaction of FLSPs (section the formulation of satisfaction of FLSP); and to minimize the cost of LSI. Section (The order allocation model for two-echelon LSSC) presents the full order allocation optimization model and the model solution is given in section (Model solution).

Problem description and assumptions: A twoechelon LSSC consisting of one LSI and several competitive FLSPs is considered. One FLSP can provide various logistics capacities and the order allocation result of one FLSP is affected by the capacities of other FLSPs. In contrast to FLSPs' passively accepting order in previous studies, we assume that FLSPs have a strategic behavior, specifically pre-estimate behavior (i.e., before 
Table 1: Notations for the model

\begin{tabular}{|c|c|}
\hline$\underline{\text { Symbol }}$ & Description \\
\hline$m$ & Species of logistics service orders \\
\hline$n$ & Quantity of FLSP \\
\hline$\pi_{i}$ & Utility of the $i^{\text {th }}$ FLSP \\
\hline$v_{i}$ & Expected utility of the unit logistics capacity provided by the $i^{\text {th }}$ FLSP \\
\hline$c_{i}$ & Operation cost of the unit logistics capacity of the $i^{\text {th }}$ FLSP \\
\hline$c_{f i}$ & Fixed cost of the $i^{\text {th }}$ FLSP participating in order allocation \\
\hline$\varepsilon_{i}$ & Expected discount coefficient of the $i^{\text {th }}$ FLSP getting the logistics service order \\
\hline$\psi_{i}$ & Competitiveness of the $i^{\text {th }}$ FLSP \\
\hline$r_{i}$ & Unit logistics capacity quoted price of the $i^{\text {th }}$ FLSP \\
\hline$b_{k i}$ & Impact factor of $r_{k}$ to $\psi_{i}$ \\
\hline$\zeta_{i}$ & Expected probability of the $i^{\text {th }}$ FLSP getting orders \\
\hline$\beta_{i}$ & Order meeting degree by the logistics capacity of the $i^{\text {th }}$ FLSP \\
\hline$k_{i}$ & Business reputation of the $i^{\text {th }}$ FLSP \\
\hline$Q_{i}$ & Logistics capacity of the $i^{\text {th }}$ FLSP \\
\hline$p_{i}$ & Unit logistics price of the $i^{t h}$ FLSP offered by LSI \\
\hline$R_{j}$ & Total demand of the $j^{\text {th }}$ logistics service order \\
\hline$x_{i j}$ & Order volume of the $j^{\text {th }}$ logistics service of the $i^{\text {th }}$ FLSP allocated by LSI \\
\hline$T_{k l}$ & Matching degree between the $k^{\text {th }}$ logistics service capacity and the $l^{\text {th }}$ logistics service capacity \\
\hline$\delta_{i k l}$ & Unmatching degree between the $k^{\text {th }}$ logistics service capacity and the $l^{\text {th }}$ logistics service capacity provided by the $i^{\text {th }}$ FLSP \\
\hline$d_{i j 1}$ & Quantity satisfaction of the $i^{\text {th }}$ FLSP \\
\hline$d_{i j 2}$ & Price satisfaction of the $i^{\text {th }}$ FLSP \\
\hline$d_{i}$ & Order allocation satisfaction of the $i^{\text {th }}$ FLSP \\
\hline$v_{i j}^{0}$ & Lowest income of unit logistics capacity acquired by the $i^{t h}$ FLSP participating in the allocation of the $j^{t h}$ logistics service order \\
\hline$d_{i j 2}{ }^{0}$ & Initial price satisfaction of the $i^{\text {th }}$ FLSP with the $j^{\text {th }}$ logistics service order \\
\hline$w_{i 1}$ & Quantity satisfaction weight of the $i^{\text {th }}$ FLSP \\
\hline$w_{i 2}$ & Price satisfaction weight of the $i^{\text {th }}$ FLSP \\
\hline$p_{i j}$ & Unit logistics capacity price of LSI buying the $j^{\text {th }}$ logistics service order from the $i^{\text {th }}$ FLSP \\
\hline$v_{i j}$ & Utility of the $j^{\text {th }}$ logistics service order from the $i^{\text {th }}$ FLSP \\
\hline$\varepsilon_{i j}$ & Expected discount coefficient of the $i^{\text {th }}$ FLSP getting the $j^{\text {th }}$ logistics services order \\
\hline$Q_{i j}$ & Logistics capacity of the $i^{\text {th }}$ FLSP providing the $j^{\text {th }}$ logistics services order \\
\hline$c_{i j}$ & Operation cost of unit logistics capacity of the $i^{\text {th }}$ FLSP participating in the allocation of the $j^{\text {th }}$ logistics services order \\
\hline$c_{f i j}$ & Fixed cost of the $i^{\text {th }}$ FLSP participating in the allocation of the $j^{\text {th }}$ logistics services order \\
\hline$Z_{1}$ & Total cost of LSI \\
\hline$Z_{2}$ & Order satisfaction of FLSP \\
\hline$Z_{3}$ & Capacity matching degree of FLSP \\
\hline$Z^{\min }{ }_{1}$ & Minimum total cost of LSI \\
\hline$Z_{2}^{\max }$ & Maximum order satisfaction of FLSP \\
\hline$Z^{\min }{ }_{3}$ & Optimal capacity matching degree of FLSP \\
\hline$\varphi(Z)$ & Index of comprehensive performance of LSSC \\
\hline
\end{tabular}

cooperating with LSI, FLSPs will estimate the possibility of acquiring the orders, establish a profit function to gain the critical condition of order allocation and finally decide whether or not to participate in order allocation. Meanwhile, LSI will make order allocation decisions by considering the pre-estimate behavior of the FLSPs).

The LSSC is assumed to consist of one LSI, $n$ FLSPs and $m$ types of logistics service orders, in which the total logistics service demand of order $\mathrm{j}(1 \leq \mathrm{j} \leq \mathrm{m})$ is $\mathrm{R}_{\mathrm{j}}$ and the $j^{\text {th }}$ order quantity of the $i^{\text {th }}$ FLSP allocated by LSI is $x_{i j}$. The capacity of each FLSP is also independent and no correlation is observed. Considering the uncertainty of customer demand, $R_{j}$ is assumed to be a random variable following normal distribution $\mathrm{N}\left(\mu_{\mathrm{j}}, \sigma^{2}{ }_{\mathrm{j}}\right)$. Meanwhile, Prob $\left(\sum_{i=1} x_{i j} \geq\right.$ $R_{j}$ ) represents the opportunity constraints provided by the total capacity of FLSPs in meeting customer demand for the $j^{\text {th }}$ order and $\alpha$ represents the probability of meeting customer demand. For example, when $\alpha=90 \%$, the total capacity of FLSPs can meet at least $90 \%$ of customer demand. According to Liu et al. (2011), the uncertain demand constraint can be transformed into a certain one; however, the total capacity of FLSPs should meet the following constraint:

$$
\sum_{i=1}^{n} x_{i j}=\mu_{j}+\Phi^{-1}(\alpha) \sigma_{j}
$$

where, $\Phi^{-1}(\alpha)$ is the inverse function of standard normal distribution $\Phi(x)$.

The notations involved in the model are shown in Table 1.

Rational expectation constraint of FLSP considering REE and competition behavior: In this section, the utility function of FLSP will be formulated firstly. Then, the competitiveness of FLSP in order allocation is expressed. Lastly, when participating in order allocation, FLSP will give an expectation of the probability of getting the order; the rational expectations constraint of each FLSP's participation in order allocation is given.

Utility function of FLSP: In the order allocation process, FLSPs will pre-estimate the order allocation 
results according to their logistics service capacity and the order demand from LSI. Participating in order allocation, the $i^{\text {th }}$ FLSP will be faced with two conditions: acceptance or refusal. When accepting an order, the utility of the FLSP is equal to the utility of providing logistics services capacity minus logistics operation cost and fixed cost; when refusing an order, the utility of the FLSP is equal to the negative of fixed cost of participating in order allocation. The utility function $\pi_{i}$ can be expressed as follows:

$$
\pi_{i}= \begin{cases}\left(v_{i} q_{i}-c_{i} q_{i}\right)-c_{f i} & \text { if } i^{t h} \text { FLSP get order } \\ -c_{f i} & \text { if } i^{t h} \text { FLSP get no order }\end{cases}
$$

where $v_{i}$ represents the expected utility of unit logistics capacity provided by the $i^{\text {th }}$ FLSP and qirepresents the expected order quantity of the $i^{\text {th }}$ FLSP. Here we introduce an expected discount coefficient, $\mathrm{q}_{\mathrm{i}}=\varepsilon_{\mathrm{i}} / \mathrm{n} \mathrm{Q}_{\mathrm{i}}$ and $\varepsilon_{\mathrm{i}} \leq 1$, which means $\mathrm{q}_{\mathrm{i}}$ decreases with the increase of FLSPs involved in order allocation.

$Q_{i}:$ Represents the logistics capacity of the $i^{\text {th }}$ FLSP

$c_{i}$ : Represents the operation cost of unit logistics capacity of the $i^{\text {th }}$ FLSP

$c_{f i}$ : Represents the fixed cost of the $i^{\text {th }}$ FLSP participating in order allocation.

Competitiveness of FLSPs: When FLSPs compete for an order, the competitiveness of the $i^{\text {th }}$ FLSP can be expressed as follows:

$$
\Psi_{i}=\frac{1}{r_{i}+\sum_{k \neq i} b_{k i}\left(r_{i}-r_{k}\right)}
$$

where, $r_{i}$ represents the unit logistics capacity quoted price that the $i^{\text {th }}$ FLSP requires from LSI; $b_{k i} \in(0,1]$ represents the impact factor of $r_{k}$ to the competitiveness of the $i^{t h}$ FLSP. We assume that all FLSPs have the same status and their provided logistics services are homogeneous. Therefore, $b_{k i}$ is the equal for any FLSP.

REE between FLSP and LSI: When participating in order allocation, the $i^{\text {th }}$ FLSP will give an expectation of the probability of getting the order. Assuming that the expected probability for the $i^{\text {th }}$ FLSP to get the order is $\zeta_{\mathrm{i}}, \zeta_{\mathrm{i}}$ is associated with the competitiveness of the $i^{\text {th }}$ FLSP, $\psi_{i}$, the degree to which the self-logistics capacity satisfies the order, $\beta_{i}$ and business reputation $k_{i}$; thus, $\zeta_{i}$ and $\beta_{i}$ can be expressed as follows:

$$
\zeta_{i}=c_{i} \kappa_{i} \beta_{i} \Psi_{i}
$$

$$
\beta_{i}=\frac{Q_{i}}{R}
$$

where, $Q_{i}$ represents the logistics capacity of the $i^{t h}$ FLSP and $R$ represents the total demand of the logistics service order. We assume that the business reputation of the $i^{\text {th }}$ FLSP is $\mathrm{k}_{\mathrm{i}}, \mathrm{k}_{\mathrm{i}} \in(0,1)$.

Equation (4) and (5) show that the FLSPs with a larger capacity and higher business reputation can expect a greater probability of getting the order and FLSPs with higher prices will have a lower expected probability.

Based on Eq. (2), we can conclude that to ensure the $i^{\text {th }}$ FLSP participates in order allocation, it must meet the requirement that the utility of the FLSP getting orders must be more than that of getting an order, that is:

$$
\zeta_{i}\left[\left(v_{i} q_{i}-c_{i} q_{i}\right)-c_{f i}\right] \geq\left(1-\zeta_{i}\right)\left(-c_{f i}\right)
$$

Substituting Eq. (3) and (4) into Eq. (5), the equation can be rewritten as follows:

$$
v_{i} \geq \frac{c_{f i}}{\zeta_{i} q_{i}}+c_{i}=\frac{n c_{f i} R\left[r_{i}+\sum_{k \neq i} b_{k i}\left(r_{i}-r_{k}\right)\right]}{c_{i} \kappa_{i} \varepsilon_{i} Q_{i}^{2}}+c_{i}
$$

As $v_{i} \geq c_{i}$, based on Eq. (6), the following equation can be obtained:

$$
r_{i}+\sum_{k \neq i} b_{k i}\left(r_{i}-r_{k}\right) \geq 0
$$

According to the REE, the unit logistics capacity price offered by LSI is equal to the expected utility of unit logistics capacity provided by the FLSP and the unit logistics capacity quoted price of the FLSP is equal to the expected utility of unit logistics capacity provided by the FLSP, which can be presented as follows:

$$
p_{i}=v_{i}, r_{i}=v_{i}
$$

Substituting Eq. (8) into Eq. (7), we thus have:

$$
p_{i}+\sum_{k \neq i} b_{k i}\left(p_{i}-p_{k}\right) \geq 0
$$

Substituting Eq. (8) into Eq. (6), the following equation can be easily obtained:

$\left[\kappa_{i} \varepsilon_{i} c_{i} Q_{i}^{2}-n c_{f i} R(1+b n-b)\right] v_{i}+n c_{f i} R b_{k i} \sum_{k \neq i} v_{k} \geq \kappa_{i} \varepsilon_{i} Q_{i}^{2} c_{i}^{2}$ 
Equation (10) represents the rational expectations constraint of each FLSP's participation in order allocation.

Order allocation model for two-echelon LSSC: When allocating orders to FLSPs, LSI pursues the minimum of total cost while considering the capacity matching degree and satisfaction of FLSPs. Therefore, we will discuss the expression of the capacity matching degree of FLSPs in section (The formulation of capacity matching degree), explore the expression of FLSPs' satisfaction in section (The formulation of satisfaction of FLSP) and then establish the order allocation model in section (The order allocation model for two-echelon LSSC).

The formulation of capacity matching degree: Logistics service is the integration of various functional logistics services; hence, it requires different logistics service capacities to match each other as much as possible. In actual operations, when allocating orders to FLSPs, LSI usually requires FLSPs to match different capacities as much as possible. For example, according to the requirement that transportation capacity should match the warehousing capacity, if FLSP A provides 500 highway transportation vehicles, it should provide 1,000 square meters of warehouse space as far as possible; if FLSP A cannot provide warehouse space or can only provide 500 square meters of warehouse space, then the transportation capacity provided by FLSP A does not completely match the warehousing capacity.

Matching degree is introduced to describe the capacity-matching conditions of FLSPs. Let $T_{k l}$ represent the matching degree between the $k^{\text {th }}$ logistics service capacity and the $l^{\text {th }}$ logistics service capacity; if $k=l$, then $T_{k l}=1 ; T_{k l}=1 / T_{l k}$. Under the incomplete matching condition, $\delta_{\mathrm{ikl}}$ denotes the unmatched degree between the $k^{\text {th }}$ logistics service capacity and the $l^{\text {th }}$ logistics service capacity provided by the $i^{\text {th }}$ FLSP, $\delta_{i k l}$ $=0$ denotes "completely matched," and $\delta_{i k l}=1$ denotes "completely unmatched". Therefore:

$$
\delta_{i k l}=\frac{\left|\frac{x_{i k}}{x_{i l}}-T_{k l}\right|}{T_{k l}}
$$

Considering $\mathrm{x}_{\mathrm{il}}$ may be equal to 0 , Eq. (11) can be written as Eq. (12):

$$
\delta_{i k l}= \begin{cases}\frac{\left|\frac{x_{i k}}{x_{i l}}-T_{k l}\right|}{T_{k l}} x_{i l} \neq 0 \\ 1 & x_{i l}=0\end{cases}
$$

Unmatched capacity will generate coordination costs. To avoid the extra costs, LSI requires FLSPs to match their capacities as much as possible, namely, to $\operatorname{minimize} \sum_{i=1}^{n} \sum_{l=1}^{m} \sum_{k=1}^{i} \delta_{i k l}$.

The formulation of satisfaction of FLSP: Based on the assumption of Liu et al. (2011), the satisfaction of the $i^{\text {th }}$ FLSP is composed of quantity satisfaction $d_{i j 1}$ and price satisfaction $\mathrm{d}_{i j 2}$. Quantity satisfaction reflects the relation of the $i^{\text {th }}$ FLSP's order quantity, $\mathrm{x}_{\mathrm{ij}}$ and its own capacity, $\mathrm{Q}_{\mathrm{ij}}$ and price satisfaction indicates the FLSPs' satisfaction to the price given by LSI. $d_{i j 1}$ and $\mathrm{d}_{i j 2}$ can be presented as follows:

$$
\begin{aligned}
& d_{i j 1}= \begin{cases}\frac{Q_{i j}}{x_{i j}} & x_{i j}>Q_{i j} \\
\frac{x_{i j}}{Q_{i j}} & x_{i j} \leq Q_{i j}\end{cases} \\
& d_{i j 2}=d_{i j 2}{ }^{0}+\frac{p_{i j}-v_{i j}{ }^{0}}{p_{i j}}\left(1-{\left.d_{i j 2}{ }^{0}\right)}^{0}\right.
\end{aligned}
$$

where, $\mathbf{v}_{i j}{ }^{0}$ denotes the lowest income of unit logistics capacity acquired by the $i^{\text {th }}$ FLSP participating in the $j^{\text {th }}$ order allocation. Therefore, based on Eq. (10), the following equation can be obtained:

$$
\left[\kappa_{i} \varepsilon_{i} c_{i} Q_{i}^{2}-n c_{i i} R(1+b n-b)\right] v_{i j 0}+n c_{f i} R b_{j i} \sum_{j \neq k} v_{i k 0}=\kappa_{i} \varepsilon_{i} Q_{i}^{2} c_{i}^{2}
$$

Solving Eq. (15), $\mathrm{v}_{i j}{ }^{0}$ can be written as follows:

$$
v_{i j 0}=\frac{\kappa_{i} \varepsilon_{i} Q_{i}^{2} c_{i}^{2}-n c_{f i} R b_{j i} \sum_{j \neq k} v_{i k 0}}{\kappa_{i} \varepsilon_{i} c_{i} Q_{i}^{2}-n c_{f i} R(1+b n-b)}
$$

where, $\mathrm{d}_{i j 2}{ }^{0}$ is the initial price satisfaction of the $i^{\text {th }}$ FLSP with the $j^{\text {th }}$ logistics service order when the unit price offered by LSI is $\mathrm{v}_{i j}{ }^{0}$.

Assuming that $\mathrm{w}_{\mathrm{i} 1}$ denotes the quantity satisfaction weight of the $i^{\text {th }}$ FLSP, $w_{\mathrm{i} 2}$ denotes the price satisfaction weight and $\mathrm{w}_{\mathrm{i} 1}$ and $\mathrm{w}_{\mathrm{i} 2}$ satisfy $\mathrm{w}_{\mathrm{i} 2}+\mathrm{w}_{\mathrm{i} 2}=1$ the specific value of $w_{i 1}$ and $w_{i 2}$ can be obtained through a questionnaire. The final order allocation satisfaction of the $i^{\text {th }}$ FLSP can be described as:

$$
d_{i}=\frac{1}{m}\left(w_{i 1} \sum_{j=1}^{m} d_{i j 1}+w_{i 2} \sum_{j=1}^{m} d_{i j 2}\right)
$$

The order allocation model for two-echelon LSSC: In this study, the order allocation model of the LSSC should satisfy the following objectives: 
- To minimize the cost of LSI $\left(\mathrm{Z}_{1}\right)$

- To maximize the average order satisfaction of FLSPs $\left(\mathrm{Z}_{2}\right)$

- To match the different logistics capacities of the FLSPs as much as possible $\left(\mathrm{Z}_{3}\right)$

- To meet the conditions of participating in order allocation established by the FLSPs (constraints)

According to these objectives and constraints, the optimization model of a two-echelon LSSC order allocation is as follows:

$$
\begin{aligned}
& \min Z_{1}=\sum_{i=1}^{n} \sum_{j=1}^{m} p_{i j} x_{i j} \\
& \max Z_{2}=\frac{1}{m n} \sum_{i=1}^{n}\left(w_{i 1} \sum_{j=1}^{m} d_{i j 1}+w_{i 2} \sum_{j=1}^{m} d_{i j 2}\right) \\
& \min Z_{3}=\sum_{i=1}^{n} \sum_{l=1}^{m} \sum_{k=1}^{l} \delta_{i k l} \\
& \text { s.t. }\left\{\begin{array}{l}
\sum_{i=1}^{n} x_{i j}=\mu_{j}+\Phi^{-1}(\alpha) \sigma_{j} \\
\left.\left.\kappa_{i j} \varepsilon_{i j} c_{i j} Q_{i j}{ }^{2}-n \sum_{f i} R(1+b n-b)\right] p_{i j}+n c_{k i} R b_{k i} \sum_{k \neq i} p_{k j} \geq \kappa_{i j} \varepsilon_{i j} Q_{i j}{ }^{2} c_{i j}{ }^{2}-p_{k j}\right) \geq 0 \\
p_{i j} \geq c_{i j} \\
x_{i j} \geq 0, i=1,2, \cdots n
\end{array}\right.
\end{aligned}
$$

Model solution: The model above represents a multiobjective programming problem. Given the incompatibility and incommensurability among the goals of multi-objective decision-making problems, finding an absolutely optimal solution is difficult. At present, special solutions have been developed for solving the multi-objective uncertainty issue, such as evaluation function methods (including linear weighted method, reference target method and maximumminimum method), goal programming, layered sequential method, interactive programming and membership function method, among others. In this study, we adopt the ideal point method to find the solution to nonlinear multi-objective programming.

The main steps of the ideal point method can be described as follows: if there are $r$ goals in multiobjective programming, we initially need to find the optimal value of each single goal. Recall that $Z_{\mathrm{i}}^{*}$ denotes the optimal values of the $i^{\text {th }}$ single goal. Then, $Z^{*}=\left(Z_{1}{ }^{*}, Z_{2}{ }^{*}, \ldots, Z^{*}, \ldots, Z_{r}{ }^{*}\right)$ is regarded as the ideal point. Finally, we need to find a value nearest to $Z^{*}$, which is the optimal solution to the multi-objective programming problem.
As each objective function may have different dimensions, the results should be normalized. For example, in the order allocation model presented in this study, the three objective functions-the total cost of LSI, satisfaction and the capacity-matching degree of the FLSP-are different in dimension; hence, each of them has to be normalized. Consequently, we can rewrite the objective functions of this model as follows:

$$
\begin{aligned}
& \min Z_{1}^{\prime}=\frac{Z_{1}^{\min }}{Z_{1}} \\
& \max Z_{2}^{\prime}=\frac{Z_{2}}{Z_{2}^{\max }} \\
& \min Z_{3}^{\prime}=\frac{Z_{3}^{\min }}{Z_{3}}
\end{aligned}
$$

where, $\mathrm{Z}^{\mathrm{min}}{ }_{1}$ denotes the minimum total cost of LSI, $\mathrm{Z}^{\mathrm{min}}{ }_{2}$ denotes the maximum order satisfaction of FLSPs and $\mathrm{Z}^{\mathrm{min}}{ }_{3}$ denotes the optimal capacity matching degree of FLSPs.

Then, we obtain the ideal point of this model $Z^{*}=$ $\left(Z_{1}, Z_{2}, Z_{3}\right)$. The solution to obtain the nearest value to $Z^{*}$ can be expressed as:

$$
\min \varphi(Z)=\sqrt{\left(Z_{1}-Z_{1}^{\prime}\right)^{2}+\left(Z_{2}-Z_{2}^{\prime}\right)^{2}+\left(Z_{3}-Z_{3}^{\prime}\right)^{2}}
$$

Equation (23) is the optimal solution of this order allocation problem.

In addition, given that $Z_{1}$ and $Z_{3}$ are the optimization objectives of LSI and $Z_{2}$ is the optimization objective of FLSPs, from the perspective of management science, $\varphi(Z)$ can be viewed as a comprehensive performance indicator of the LSSC that fully considers the three objective functions $Z_{1}, Z_{2}$ and $Z_{3}$. A smaller value of $\varphi(Z)$ indicates a better performance of the LSSC.

\section{NUMERICAL ANALYSIS}

Assuming that LSI B provides logistics services to a manufacturing enterprise and allocates the orders from the manufacturing enterprise to five FLSPs $\left(A_{1}\right.$, $A_{2}, A_{3}, A_{4}$ and $A_{5}$ ), to satisfy customer demand, $B$ has to provide transportation and warehousing services. In addition, assuming that the transportation service demand follows the normal distribution $N(200,25)$, the warehousing service demand follows the normal distribution $N(130,16)$ and the probability of meeting customer demand $\alpha$ is $95 \%$, LSI B requires that the two logistics capacities provided by each FLSP meet the following condition as much as possible: the ratio of transportation capacity to the warehousing capacity equals 20/13. For convenient examination, we could 
Res. J. Appl. Sci. Eng. Technol., 6(12): 2141-2152, 2013

Table 2: Parameters of FLSPs

\begin{tabular}{llllllllllll}
\hline FLSP & $c_{i 1}$ & $c_{i 2}$ & $\mathrm{k}_{\mathrm{i}}$ & $Q_{i 1}$ & $Q_{i 2}$ & $w_{i 1}$ & $w_{i 2}$ & $\mathrm{~d}_{\mathrm{i} 22}{ }^{0}$ & $\mathrm{di}_{22}{ }^{0}$ & $\varepsilon_{i 1}$ & $\varepsilon_{\mathrm{i} 2}$ \\
\hline $\mathrm{A}_{1}$ & 10 & 15 & 0.80 & 70 & 40 & 0.4 & 0.6 & 0.20 & 0.30 & 0.8 & 0.8 \\
$\mathrm{~A}_{2}$ & 8 & 13 & 0.70 & 40 & 35 & 0.5 & 0.5 & 0.35 & 0.35 & 0.5 & 0.9 \\
$\mathrm{~A}_{3}$ & 9 & 16 & 0.90 & 90 & 40 & 0.3 & 0.7 & 0.35 & 0.30 & 0.9 & 0.7 \\
$\mathrm{~A}_{4}$ & 12 & 20 & 0.60 & 60 & 50 & 0.6 & 0.4 & 0.15 & 0.20 & 0.7 & 0.9 \\
$\mathrm{~A}_{5}$ & 11 & 18 & 0.85 & 80 & 40 & 0.65 & 0.35 & 0.25 & 0.30 & 0.8 & 0.6 \\
\hline
\end{tabular}

Table 3: Order allocation results considering REE and competitive environment

\begin{tabular}{lllllllll}
\hline FLSP & $\begin{array}{l}\text { Quantity of } \\
\text { transportation } \\
\text { service }\end{array}$ & $\begin{array}{l}\text { Price of unit } \\
\text { transportation } \\
\text { service }\end{array}$ & $\begin{array}{l}\text { Quantity of } \\
\text { warehousing } \\
\text { service }\end{array}$ & $\begin{array}{l}\text { Price of unit } \\
\text { warehousing } \\
\text { service }\end{array}$ & $\begin{array}{l}\text { Total } \\
\text { cost of } \\
\text { LSI }\end{array}$ & $\begin{array}{l}\text { Satisfaction } \\
\text { of FLSPs }\end{array}$ & $\begin{array}{l}\text { Capacity } \\
\text { unmatcing } \\
\text { degree }\end{array}$ & $\begin{array}{l}\text { Comprehensive } \\
\text { performance of } \\
\text { LSSC }\end{array}$ \\
\hline $\mathrm{A}_{1}$ & 40.62 & 12.46 & 26.38 & 16.62 & 4817.1 & 0.5043 & 0.0467 & 0.3215 \\
$\mathrm{~A}_{2}$ & 39.84 & 8.11 & 26.38 & 14.50 & & & & \\
$\mathrm{~A}_{3}$ & 39.47 & 11.36 & 25.65 & 18.71 & & & & \\
$\mathrm{~A}_{4}$ & 42.58 & 13.05 & 28.00 & 20.91 & & & & \\
$\mathrm{~A}_{5}$ & 45.70 & 11.36 & 30.18 & 19.16 & & & \\
\hline
\end{tabular}

Table 4: Comparison of results in different circumstances

\begin{tabular}{lllll}
\hline Circumstance considered & Total cost of LSI & Satisfaction of FLSPs & Capacity unmatcing degree & Comprehensive performance of LSSC \\
\hline Considering REE and competitive behavior & 4817.1 & 0.5043 & 0.0467 & 0.3215 \\
Considering REE but not competitive behavior & 4936 & 0.4977 & 0.0514 & 0.2826 \\
Without REE and competition & 4603.2 & 0.4968 & 0.0518 & 0.2850 \\
\hline
\end{tabular}

When only considering competitive behavior and ignoring REE, the optimization model changes a lot. Therefore, this circumstance is not considered

assume $b_{\mathrm{ki}}=0.5,(\mathrm{k}=1,2,3,4,5 ; i=1,2,3,4,5)$. The related parameters of the transportation and warehousing capacities of $\mathrm{A}_{1}, \mathrm{~A}_{2}, \mathrm{~A}_{3}, \mathrm{~A}_{4}$ and $\mathrm{A}_{5}$ are displayed in Table 2 .

MATLAB 7.8 is used to verify the properties of the proposed optimization model via a series of numerical analyses. The order allocation results based on the REE and competition among FLSPs are provided in section (Comparison of allocation results between competitive and non-competitive environments). To further examine the variation of allocation results in a competitive environment, the effects of competition intensity and the addition of new FLSPs on order allocation are investigated. More details are provided in sections (Effects of competition intensity on order allocation) and (Effects of adding new FLSPs on order allocation).

Comparison of allocation results between competitive and non-competitive environments: Order allocation results considering REE and competitive environment are presented in Table 3. According to Table 3, the total cost of LSI is 4,817.1, the capacity unmatching degree equals 0.0467 and the comprehensive performance of LSSC is 0.3215 .

To better observe the changes brought by REE and the competitive behavior of FLSPs to order allocation results, we further explore the results of the circumstances that only consider REE or the competitive behavior of FLSPs and discuss the results of the conditions without REE and competition. We then compare these results with the data in Table 3, which are presented in Table 4.

According to Table 4, the competitive behavior of FLSPs will bring about a decline in the total cost of LSI and an increase in satisfaction of FLSPs, but lowers the capacity-matching degree, which leads to a drop in
Table 5: Effects of competition intensity on order allocation

\begin{tabular}{lll}
\hline $\mathrm{b}_{\mathrm{ki}}$ & Total cost of LSI & Order satisfaction of FLSPs \\
\hline 0.2 & 4870.1 & 0.5035 \\
0.3 & 4865.2 & 0.5030 \\
0.4 & 4863.8 & 0.5009 \\
0.5 & 4817.1 & 0.5043 \\
0.6 & 4813.3 & 0.5079 \\
0.7 & 4778.8 & 0.4980 \\
0.8 & 4763.3 & 0.4977 \\
0.9 & 4756.1 & 0.4899 \\
\hline
\end{tabular}

service supply chain performance. Therefore, based on REE, the competitive behavior of FLSPs in the model can bring improvement to the total cost of LSI and satisfaction of FLSPs.

Effects of competition intensity on order allocation: $b_{k i}$ can be used to characterize competition intensity between FLSPs. The greater the $b_{k i}$, the more intense the competition among FLSPs and vice versa. Letting $b_{\mathrm{ki}}$ vary within the interval $(0.2,0.9)$ and keeping other parameters constant, we observe the effect of competition intensity on order allocation. The results are shown in Table 5 and Fig. 1 and 2.

As shown in Fig. 1, with the increase in competition intensity among FLSPs, the total cost gradually reduces and eventually stabilizes. These changes are caused by more intense competition; FLSPs with high quotation will lose their competitiveness. In this case, they have only two choices: to provide a lower quotation or to withdraw from the competition, both of which bring the cost down for LSI.

An interesting discovery is obtained from Fig. 2. The satisfaction of FLSPs presents a trend of an initial drop, a subsequent rise and an ultimate drop with the growth of competition intensity. This phenomenon can be explained as follows: Each FLSP gets a certain number of orders and feels more satisfied in the incomplete competition situation. When competition 
Res. J. Appl. Sci. Eng. Technol., 6(12): 2141-2152, 2013

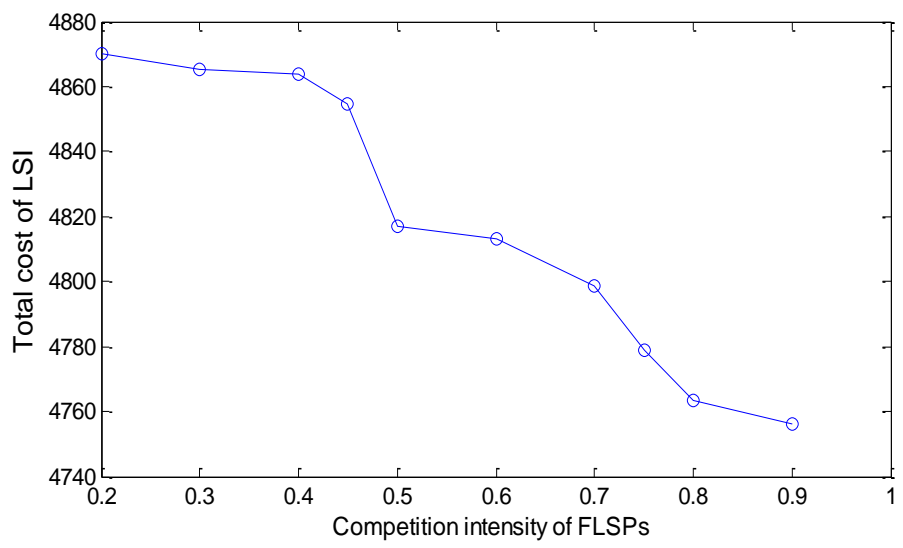

Fig. 1: Effects of competition among FLSPs on total cost

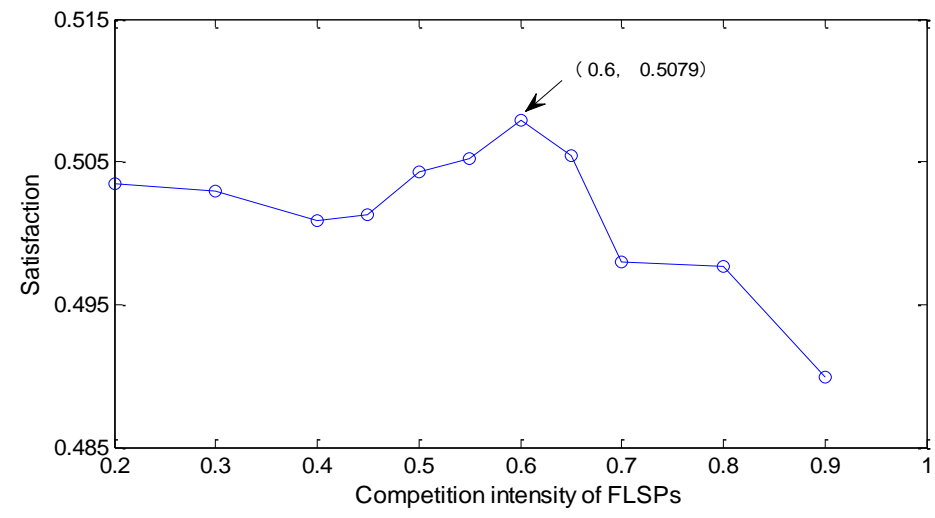

Fig. 2: Effects of competition among FLSPs on satisfaction

intensity grows, FLSPs will gradually reduce their quotation for continually participating in order allocation, which results in the decline of the price satisfaction and total satisfaction of the FLSPs. When competition is moderate, some FLSPs choose to bow out of competition as they cannot afford too low prices; the remaining FLSPs get more orders, which improve the satisfaction of FLSPs. Finally, when competition is fierce, only a small number of FLSPs can get orders from LSI with a very low price and the order quantity may exceed their service capabilities, so the satisfaction of FLSPs drops. We can conclude that, for competition intensity, an optimal value exists for the satisfaction of FLSPs and in this study, it is 0.6.

By balancing the total cost of LSI and satisfaction of FLSPs, an optimum point for competition intensity is obtained. This point can realize the goal of less cost and higher satisfaction. Therefore, too much or too little competition will adversely affect the order allocation results. Therefore, LSI should select a moderate competition intensity to acquire less cost and relatively higher satisfaction.

Effects of adding new FLSPs on order allocation: For further examination of the influence of competition, new FLSPs are added to order allocation to observe the changes in the order allocation results. New FLSPs are classified into three types: best-type FLSPs, intermediate FLSPs and worst-type FLSPs. Best-type FLSPs are the most competitive for all the parameters, such as the lowest cost, the highest initial satisfaction and the largest capacity. Worst-type FLSPs are the least competitive, with the lowest cost and the smallest capacity. The parameters of intermediate FLSPs are in the middle.

Related parameters of newly added FLSPs are presented in Table 6 . The effects brought by newly added FLSPs are discussed in the sections below.

Effects of adding the best-type FLSPs: If the number of best-type FLSPs is increased, we observe the impact on the total cost of LSSC as well as the satisfaction of FLSPs. The results are shown in Fig. 3 and 4.

Based on Fig. 3, the number of the best FLSPs does not connote the idea of "the more the better" when considering the total cost of LSI. After one best FLSP is added, the total cost falls sharply and then continually declines with the increasing number of the best FLSPs. However, when the added best FLSPs increase to a 
Res. J. Appl. Sci. Eng. Technol., 6(12): 2141-2152, 2013

Table 6: Parameters of new added FLSPs

\begin{tabular}{|c|c|c|c|c|c|c|c|c|c|c|c|}
\hline New added FLSPs & $c_{i 1}$ & $c_{i 2}$ & $\mathrm{k}_{\mathrm{i}}$ & $Q_{i 1}$ & $Q_{i 2}$ & $w_{i l}$ & $w_{i 2}$ & $\mathrm{D}_{\mathrm{il} 2}{ }^{0}$ & $\mathrm{di}_{22}{ }^{0}$ & zil & $\varepsilon_{\mathrm{i} 2}$ \\
\hline The best type & 8 & 13 & 0.9 & 90 & 50 & 0.5 & 0.5 & 0.35 & 0.35 & 0.9 & 0.9 \\
\hline The intermediate & 10 & 16.5 & 0.75 & 65 & 41.5 & 0.5 & 0.5 & 0.25 & 0.275 & 0.7 & 0.75 \\
\hline The worst type & 12 & 20 & 0.6 & 40 & 35 & 0.5 & 0.5 & 0.15 & 0.2 & 0.5 & 0.6 \\
\hline
\end{tabular}

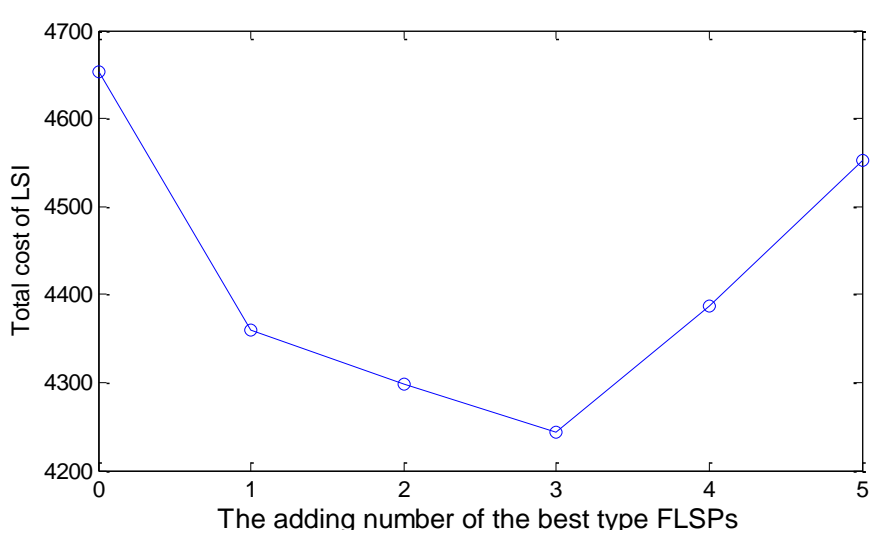

Fig. 3: Effects of adding the best-type FLSPs on total cost

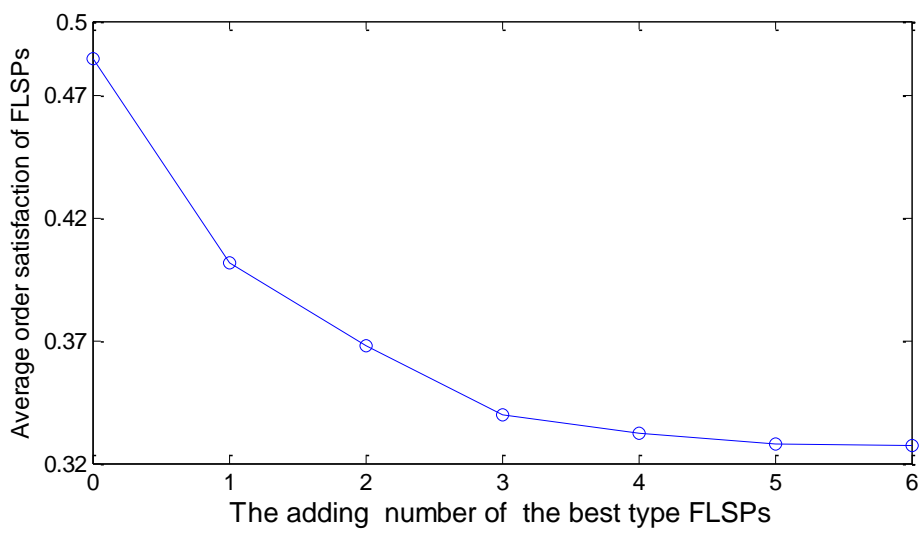

Fig. 4: Effects of adding the best-type FLSPs on satisfaction

certain number, which is three in Fig. 3 the total cost of LSI turns to an upward trend when we continue to add FLSPs.

With the increase of the added best FLSPs, the best types more possibly get the order by driving other FLSPs out of competition with their own advantages. The best FLSPs will then raise their quotation, which produces the down-up trend of the total cost.

According to Fig. 4, with the increase in the number of added best-type FLSPs, the average satisfaction of FLSPs gradually decreases, which mainly results from the low probability of each FLSP getting the order, as more FLSPs have participated in order allocation.

In summary, the appropriate number of best-type FLSPs brings the advantages of reducing total cost and improving the performance of LSI allocating orders.

Effects of adding the worst-type FLSPs: Similarly, if the number of worst-type FLSPs is increased, the impact on the total cost of LSSC and on the satisfaction of FLSPs can be observed (Fig. 5 and 6).

According to Fig. 5 and 6 , the total cost of LSI increases gradually and average satisfaction decreases gradually. Worst-type FLSPs are not adopted in order allocation despite their increasing number, so average satisfaction declines. Consequently, when adding new FLSPs to order allocation to create more competition, LSI should carefully examine the qualifications of newly added FLSPs to avoid the entry of worst-type FLSPs, which will disrupt the competitive environment and have a negative impact.

Comparison of the effects of three types of FLSPs on order allocation: Detailed data, including those on the satisfaction of FLSPs and the total cost of LSI by adding intermediate FLSPs, are obtained (Table 7). All three types of FLSPs have an impact on allocation results, but in different ways. Comparison of 
Res. J. Appl. Sci. Eng. Technol., 6(12): 2141-2152, 2013

Table 7: Order allocation results after adding new FLSPs

\begin{tabular}{|c|c|c|c|c|}
\hline \multirow[b]{2}{*}{ Index } & \multirow[b]{2}{*}{ Number of new added FLSPs } & \multicolumn{3}{|c|}{ The type of FLSPs } \\
\hline & & The best type & The intermediate type & The worst type \\
\hline \multirow[t]{5}{*}{ Total cost of LSI } & 1 & 4359.2 & 4517.0 & 4654.0 \\
\hline & 2 & 4298.8 & 4629.0 & 5094.7 \\
\hline & 3 & 4243.5 & 4711.3 & 5461.6 \\
\hline & 4 & 4386.3 & 4774.2 & 5596.7 \\
\hline & 5 & 4552.1 & 4887.9 & 5832.8 \\
\hline \multirow[t]{5}{*}{ Satisfaction of FLSPs } & 1 & 0.4013 & 0.3915 & 0.4145 \\
\hline & 2 & 0.3676 & 0.3703 & 0.4101 \\
\hline & 3 & 0.3397 & 0.3432 & 0.3820 \\
\hline & 4 & 0.3325 & 0.3206 & 0.3721 \\
\hline & 5 & 0.3280 & 0.3064 & 0.3370 \\
\hline
\end{tabular}

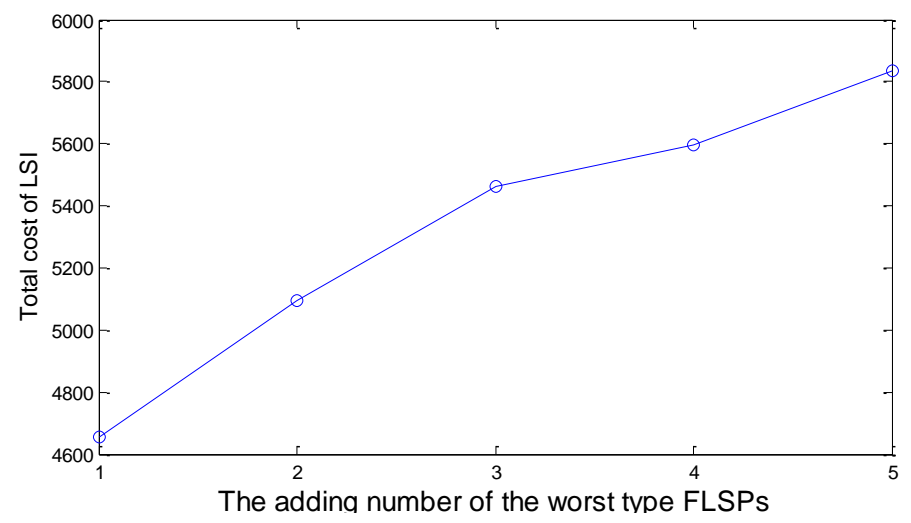

Fig. 5: Effects of adding the worst-type FLSPs on total cost

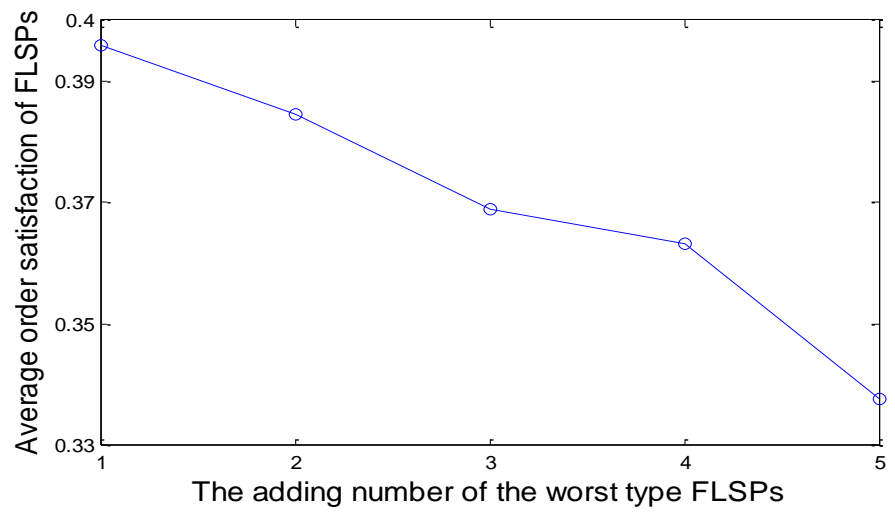

Fig. 6: Effects of adding the worst-type FLSPs on satisfaction

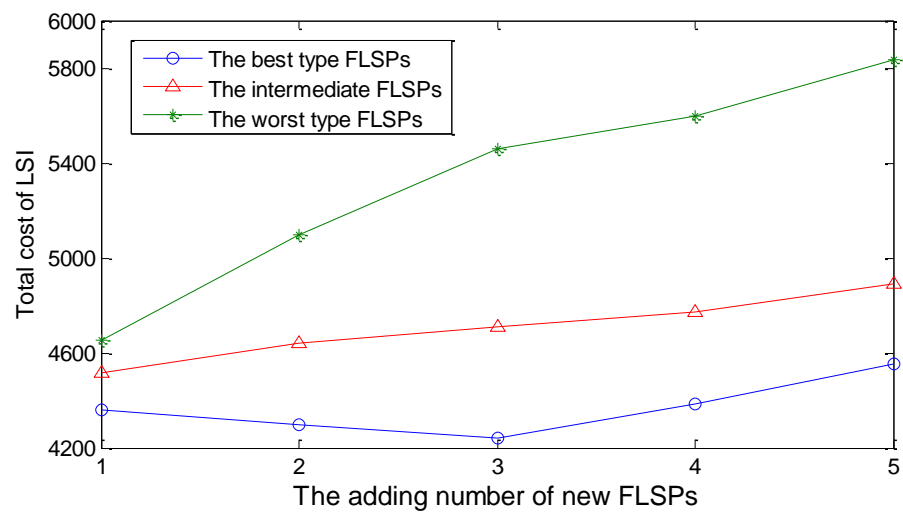

Fig. 7: Comparative study of the effects of three types of FLSPs on total cost 
Res. J. Appl. Sci. Eng. Technol., 6(12): 2141-2152, 2013

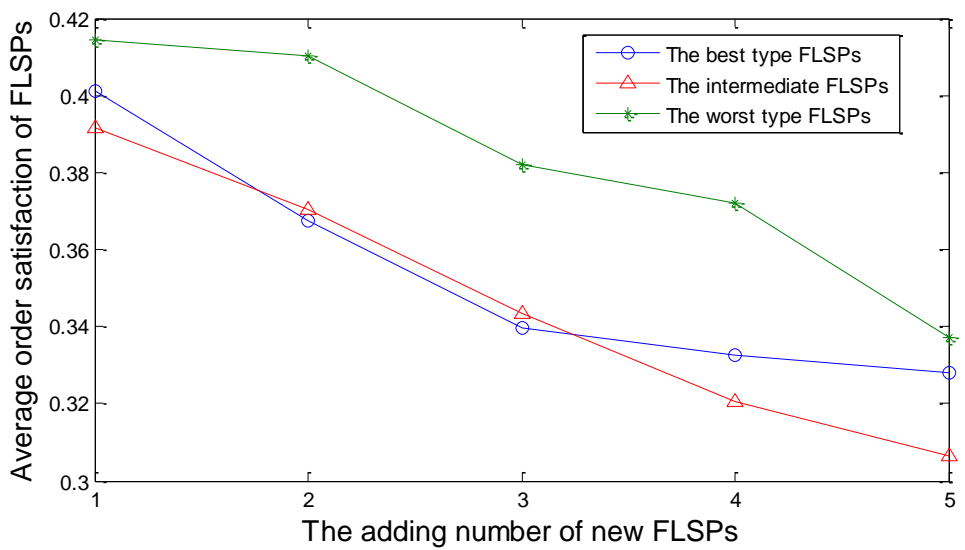

Fig. 8: Comparative study of the effects of three types of FLSPs on satisfaction

the effects of the three types of FLSPs on order allocation is shown in Fig. 7 and 8.

According to Fig. 7, when adding the same number of the three types of FLSPs, the total cost of the besttype FLSPs is the lowest, that of intermediate FLSPs follows and that of the worst-type FLSPs is the highest. This result indicates that, for total cost, the best-type FLSPs are better than intermediate FLSPs and intermediate FLSPs are better than the worst-type FLSPs.

According to Fig. 8, the average satisfaction of FLSPs shows a downward trend with the addition of new FLSPs. Moreover, when the number of best-type and intermediate FLSPs increases, average satisfaction decreases rapidly, although that of worst-type FLSPs decreases relatively slowly. The main reason for this slower decrease is that worst-type FLSPs are not accepted in order allocation; thus, quantity satisfaction and price satisfaction do not change. However, the average satisfaction of FLSPs correspondingly shows a downward trend due to the increase in the number of FLSPs.

\section{MANAGERIAL IMPLICATIONS}

Based on the numerical analysis, the following important conclusions are obtained:

First, according to Table 4, the results considering REE and competition are superior to those that do not consider these two factors. The rational forecast behavior of FLSPs and competition are conducive to enhancing the comprehensive performance of the LSSC. LSI should take advantage of these two factors to improve supply chain performance.

Second, LSI can improve the performance of the LSSC by controlling intensity. Competition can reduce the cost of LSI and make average satisfaction present a down-up-down trend. Too much or too little competition will adversely affect the order allocation results; hence, LSI should select a moderate competition intensity to acquire less cost and relatively higher satisfaction of FLSPs.
Third, LSI can add new FLSPs to improve the performance of the LSSC. When the added number of new FLSPs is the same, intermediate FLSPs and worsttype FLSPs are not a good choice, because they bring about higher cost and lower satisfaction. In addition, although the best-type FLSPs help lower cost, their number does not connote the idea of "the more the better," but should be controlled within a suitable range.

\section{CONCLUSION}

By considering uncertain demand conditions, this study discussed the order allocation model in the LSSC when the FLSP has pre-estimate behavior and competes with other FLSPs. Based on the theory of REE and on three factors (i.e., the goals of the total cost of LSI, order satisfaction of FLSPs and capacity-matching degree of FLSPs), an order allocation model was built and solved and numerical analysis was performed to discuss the effect of competition parameters on order allocation. Competition was found to be conducive to enhancing the performance of the LSSC. With the increase of competition intensity, the total cost of LSI decreased and the satisfaction of FLSPs showed a down-up-down trend. Moreover, FLSPs in different numbers and types affected the order allocation performance in different ways. Adding the best-type FLSPs is the better choice, but their number should be controlled within a suitable range.

Despite these findings, the order allocation model is still characterized by certain limitations. For example, only three goals-total costs, order satisfaction of FLSPs and capacity-matching degree-are considered and additional goals can be taken into account in a follow-up study. The model in this study is established under a single period; a multi-period environment can be investigated utilizing the behavior experiment method in future empirical research. Furthermore, the model in this study focuses on a two-echelon LSSC order allocation; a multi-stage supply chain order allocation can be considered in future studies. 


\section{ACKNOWLEDGMENT}

This study is supported by the National Natural Science Foundation of China (Grant No.70902044). The suggestions of the reviewers are also gratefully acknowledged.

\section{REFERENCES}

Babich, V., 2006. Vulnerable options in supply chains: Effects of supplier competition. Naval Res. Logist., 53(7): 656-673

Babich, V., A.N. Burnetas and P.H. Ritchken, 2007. Competition and diversification effects in supply chains with supplier default risk. Manuf. Serv. Oper. Manag., 9(2): 123-146.

Bendoly, E., K. Donohue and K.L. Schultz, 2006. Behavior in operations management: Assessing recent findings and revisiting old assumptions. J. Oper. Manag., 24(6): 737-752.

Chaharsooghi, S.K., J. Heydari and I.N. Kamalabadi, 2011. Comp. Oper. Res., 38(12): 1667-1677.

Chan, F.T.S., P.K. Humphreys and T.H. Lu, 2001. Order release mechanisms in supply chain management: A simulation approach. Int. J. Phys. Distrib. Logist. Manag., 31(1): 124-139.

Choy, K.L., C.L. Li, C.K.S. Stuart and L. Henry, 2007. Managing uncertainty in logistics service supply Chain. Int. J. Risk, 7(1): 19-22.

Demirtas, E.A. and O. Üstün, 2008. An integrated multi-objective decision making process for supplier selection and order allocation. Omega, 36(1): 76-90.

Du, B., 2009. Rational expectations equilibrium analysis on newsvendor model with information transfer. Proceeding of International Conference on Management of E-Commerce and E-Government, pp: 355-358.

Forker, L.B. and P. Stannack, 2000. Cooperation versus competition: Do buyers and suppliers really see eye-to-eye? Europ. J. Purch. Supply Manag., 6(1): $31-40$.

Ji, X.L., 2005. Order allocation model in supply chain and hybrid genetic algorithm. J. Southwest Jiaotong Univ., 40(6): 811-815, (In Chinese).

Jin, Y. and J.K. Ryan, 2012. Price and service competition in an outsourced supply chain. Prod. Oper. Manag., 21(2): 331-344.

Kawtummachai, R. and N.V. Hop, 2005. Order allocation in a multiple-supplier environment. Int. J. Prod. Econ., 94(1): 231-238.
Muth, J.F., 1961. Rational expectations and the theory of price movements. Econometrica, 29(3): 315-335.

Liu, W.H., X.C. Xu, Z.X. Ren and Y. Peng, 2011. An emergency order allocation model based on multiprovider in two-echelon logistics service supply chain. Supply Chain Manag. Int. J., 16(6): 390-400.

Menon, S. and L. Schrage, 2002. Order allocation for stock cutting in the study industry. Oper. Res., 50(2): 324-332.

PrasannaVenkatesan, S. and S. Kumanan, 2012. Multiobjective supply chain sourcing strategy design under risk using PSO and simulation. Int. J. Adv. Manuf. Technol., 61(1): 325-337.

Qi, E.S., D.J. Yang and L. Liu, 2010. Supply chain twopart tariff based on strategic customer behavior. Comp. Int. Manuf. Syst., 16(4): 828-833.

Su, X.M. and F.Q. Zhang, 2008. Strategic customer behavior, commitment and supply chain performance. Manag. Sci., 54(10): 1759-1773.

Ta, L., Y.T. Chai and Y. Liu, 2005. A multi-agent approach for task allocation and execution for supply chain management. Proceeding of IEEE Networking, Sensing and Control, pp: 65-70.

Wang, H.W., W. Zhang and L.J. Zheng, 2011. Dynamic pricing in $\mathrm{B} 2 \mathrm{C}$ based on online product reviews. Proc. Eng., 23: 270-275.

Xia, Y., B.T. Chen and P. Kouvelis, 2012. Marketbased supply chain coordination by matching suppliers' cost structures with buyers' order profiles. Manag. Sci., 54(11): 1861-1875.

Xiang, J.Q., P.Q. Huang and Z.P. Wang, 2006. Order allocation model based on profit maximization of horizontal conglomerate. J. Southwest Jiaotong Univ., 41(2): 241-244.

Yang, D.J., E.S. Qi and F. Wei, 2011. Supply chain profit sharing under strategic customer behavior and risk preference. J. Manag. Sci. China, 14(12): 50-59, (In Chinese).

Yang, Z.B., G. Aydin, V. Babich and D.R. Beil, 2012. Using a dual-sourcing option in the presence of asymmetric information about supplier reliability: Competition vs. diversification. Manuf. Serv. Oper. Manag., 14(2): 202-217.

Yue, J.F., Y. Xia and T. Tran, 2009. Selecting sourcing partners for a make-to-order supply chain. OMEGA-Int. J. Manag. Sci., 38(3): 136-144. 